\title{
Leïla Marouane, La jeune fille et la mère
}

\author{
Julie Milò
}

\section{(2) OpenEdition}

\section{Journals}

\section{Édition électronique}

URL : http://journals.openedition.org/studifrancesi/28161

DOI : 10.4000/studifrancesi.28161

ISSN : 2427-5856

\section{Éditeur}

Rosenberg \& Sellier

\section{Édition imprimée}

Date de publication : 31 décembre 2006

Pagination : 646-647

ISSN : 0039-2944

\section{Référence électronique}

Julie Milò, «Leïla Marouane, La jeune fille et la mère », Studi Francesi [En ligne], 150 (L | III) | 2006, mis en ligne le 30 novembre 2015, consulté le 08 novembre 2020. URL : http://journals.openedition.org/ studifrancesi/28161; DOI : https://doi.org/10.4000/studifrancesi.28161

\section{Ce document a été généré automatiquement le 8 novembre 2020}

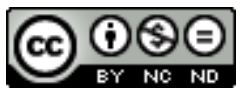

Studi Francesi è distribuita con Licenza Creative Commons Attribuzione - Non commerciale - Non opere derivate 4.0 Internazionale. 


\title{
Leïla Marouane, La jeune fille et la mère
}

\author{
Julie Milò
}

\section{RÉFÉRENCE}

LËILA MAROUANE, La jeune fille et la mère, Paris, Seuil, 2005, pp. 177.

Installée à Paris depuis 1991, Leïla Marouane se refuse de retourner vivre en Algérie tant que les lois ne seront ne seront pas favorables aux femmes. Son quatrième roman nous fait pénétrer dans le quotidien d'un foyer algérien à travers une écriture serrée dont le style et les codes adoptés reflètent les tensions existant entre les différents membres de la famille. Après l'indépendance de l'Algérie, les femmes, conscientes d'avoir joué un rôle de tout premier ordre durant la guerre, ont revendiqué la place qui leur revenait de droit dans le nouvel ordre social. Mais, au fil des années, leur attente a été fortement déçue, les promesses faites au lendemain de la décolonisation n'ont pas été maintenues et, à l'heure du désenchantement, beaucoup d'héroïnes ont tout simplement dû, malgré elles, réintégrer la tradition (cfr. Djamila Amrane, Femmes algériennes dans la guerre, 1991). Dans ce livre, la mère, une de ces anciennes combattantes, frustrée dans ses aspirations personnelles, place tous ses espoirs dans sa fille aînée qu'elle veut voir indépendante et émancipée grâce à l'instruction qu'ellemême n'a pu recevoir. Caressant son rêve, elle continue à entretenir un rapport conflictuel avec son mari qu'elle rend responsable de sa condition de mère accoucheuse et de femme soumise selon la bonne tradition arabe. Et en effet, le mari a une toute autre considération pour cette fille, déjà mal acceptée à la naissance et dont il a fini par découvrir, à travers maintes manigances, le "flagrant délit": à peine pubère, un malotru avait voulu abuser de son innocence dans un jardin public sans néanmoins y parvenir. Pour ce père sans scrupules, cette découverte ne pouvait mieux tomber: ce sera le prétexte pour arranger un mariage de raison, destiné surtout à renflouer ses poches. Loin de tomber dans le piège des manichéismes faciles, en mettant en scène un père machiste et vulgaire face à une femme brimée mais pleine de ressources, ce roman 
retient particulièrement l'attention par l'étude subtile des comportements, et, en particulier celui de la mère quand, à son tour, elle apprendra la fâcheuse histoire arrivée à son enfant. Contre toute attente, les deux époux réconciliés infligeront, d'un commun accord, à leur fillette sans défense, un châtiment corporel qui a manqué lui être fatal. La fin du livre met en scène une mère devenue folle, en proie au délire et ne répondant plus de ses actes. À aucun moment Leïla Marouane ne s'introduit dans le récit pour commenter, pour étudier les personnages ou faire le point de la situation. Elle reste en retrait et laisse parler et agir les êtres qu'elle a créés; à travers eux elle laisse voir les ravages produits par une mère qui ne sait pas être à l'écoute de sa fille parce que habitée par sa propre fixation. Leïla Marouane pose des problèmes qui sont aujourd'hui encore fondamentaux. Son roman trace le portrait non pas d'une femme émancipée grâce à sa culture et à sa force de volonté, évoluant dans un milieu privilégié, mais d'une femme ordinaire poursuivant encore une liberté toujours niée. $\mathrm{Au}$-delà de cette histoire personnelle, le thèmes évoqués sont nombreux: la persistance des tabous sexuels, la séparation entre le monde des adultes et le monde des enfants, entre la sphère des hommes et celle des femmes, le manque de dialogue et de compréhension; la solitude, l'enfermement psychologique, l'aliénation. À aucun moment la romancière n'entend donner de fausses illusions sur la condition féminine après l'indépendance, le livre ne veut pas être une hagiographie sur les nouveaux rapports institués entre les différentes générations de femmes; bien au contraire, il a surtout le mérite de soulever la question de la crise psychologique traversée par la majeure partie des résistantes une fois la guerre terminée, leur difficulté à renoncer aux avantages acquis, à assumer leur place de femme au foyer mais aussi leur désarroi face à leur rôle éducatif de mère. Prise entre l'obscurantisme de la tradition et l'obsession d'un avenir meilleur pour sa fille, la mère court inévitablement vers sa perte voulant entraîner avec elle cette enfant qui a fait s'effondrer tous ses rêves. On pourra trouver l'écrivain très dure, on lui reprochera peut-être d'avoir peint des situations de négativité extrême dans une famille où l'affectivité et l'amour semblent être totalement absents. Mais la note d'espoir réside là où on s'y attend peut-être le moins, dans le cœur des frères aînés qui, dans leur générosité spontanée et par affection pour leur jeune sœur, viendront à son secours. Leïla Marouane n'investit pas, du moins pas uniquement, dans la solidarité des femmes pour construire un futur plus souriant pour elles. Sans parti-pris féministe, plus réaliste que les romancières de l'époque coloniale ou simplement plus inscrite dans l'actualité, elle interpelle surtout les jeunes gens car, sans leur amour et sans leur complicité, les filles ne trouveront jamais leur juste place dans la société. Elle laisse entendre que l'avenir appartient aux jeunes générations lestées du poids des interdits et qui croient en un futur où viendra s'inscrire le nouveau visage de l'Algérie. 